\title{
Computational Fluid Dynamics in Torque Converters: Validation and Application
}

\author{
Jean Schweitzer and Jeya Gandham \\ GM Powertrain, Ypsilanti, Michigan, USA
}

This article describes some of the computational fluid dynamics (CFD) work being done on three-element torque converters using a commercially available package CFX TASCflow. The article details some of the work done to validate CFD results and gives examples of ways in which CFD is used in the torque-converter design process. Based on the validation study, it is shown that CFD can be used as a design and analysis tool to make decisions about design direction. Use of CFD in torque converters is a developing field. Thus, more work needs to be done before the requirement of hardware to validate designs can be fully eliminated. This article demonstrates the confidence level in torque converter CFD and demonstrates how it can be used to assist torqueconverter design today.

Keywords Computational fluid dynamics (CFD), Torque converter, Turbomachinery

Analyzing fluid flow within a torque converter using computational fluid dynamics (CFD) is a developing field. The close coupling of the elements in a torque converter and the fact that it is a closed-loop turbomachine give rise to complicated flows within a torque converter. The flow is threedimensional, and secondary flows are present. To improve the

Received 25 June 2002; accepted 1 July 2002.

The authors thank Don Maddock, manager of the Advanced Torque Converter Group at GM Powertrain, for his support and direction. Appreciation also goes to Professor Ronald Flack at the Department of Mechanical and Aerospace Engineering of the University of Virginia and his students for their work on LDV measurements inside the torque converter. Likewise, thanks to Dr. Budugar Lakshminarayana at the Center for Gas Turbine and Power, Department of Aerospace Engineering, at The Pennsylvania State University and his students for their work with aerodynamic probe measurements inside the torque converter.

Address correspondence to Jean Schweitzer, Advanced Power Transfer, GM Powertrain, MC 481-700-718, P.O. Box 935, Ypsilanti, MI 48197-0935, USA. E-mail: jean.m.schweitzer@gm.com

performance of a torque converter, it is necessary to understand the flow of fluid within it. CFD can simulate this flow and thus can be used as an analysis and design tool. This article presents a comparison of CFD results with laser Doppler velocimetry (LDV) data, probe data, and dynamometer data. Velocity profiles at various locations in a torque converter are compared with LDV data, and pressure profiles are compared with probe data. A comparison of the standard performance parameters of a set of converters with dynamometer data is presented.

Some of the applications of CFD in torque converter design and study are also presented. It has been used in element design, torus design, and cavitation study. CFD analysis results have also been used to optimize designs before fabricating experimental hardware.

\section{GRID DEFINITION}

In the pump and the turbine, one blade-centered H-grid block was constructed as shown in Figure 1a and b. Block-structured, boundary-fitted, nonorthogonal grids were constructed using the grid generator CFX Turbogrid (AEA Technology, 2000a). The grid elements inside the blade were blocked off and the grid lines were concentrated near solid walls. This is a simple topology that makes it easy to apply boundary conditions and do postprocessing.

In the stator, a blade-centered O-grid and $\mathrm{C}$-grid were constructed (Fig. 2a and b). The O-grid was constructed all around the blade, achieving nearly orthogonal elements on the blade and good boundary-layer resolution. The C-grid was placed in the blade passage and around the blade's leading edge. This type of grid is well suited for boundary attachment and periodic connectivity. Two H-grid blocks were placed on the trailing edge, as this type of grid is well suited for a high blade trailing-edge angle.

The complete model for the pump, turbine, and stator is shown in Figure 3. The grid in the pump and turbine consisted of 22,500 nodes, and the stator grid had 35,000 nodes. Finer grids have been used, but it was found that this grid is sufficient for rapid CFD work and for practical industrial calculations. 

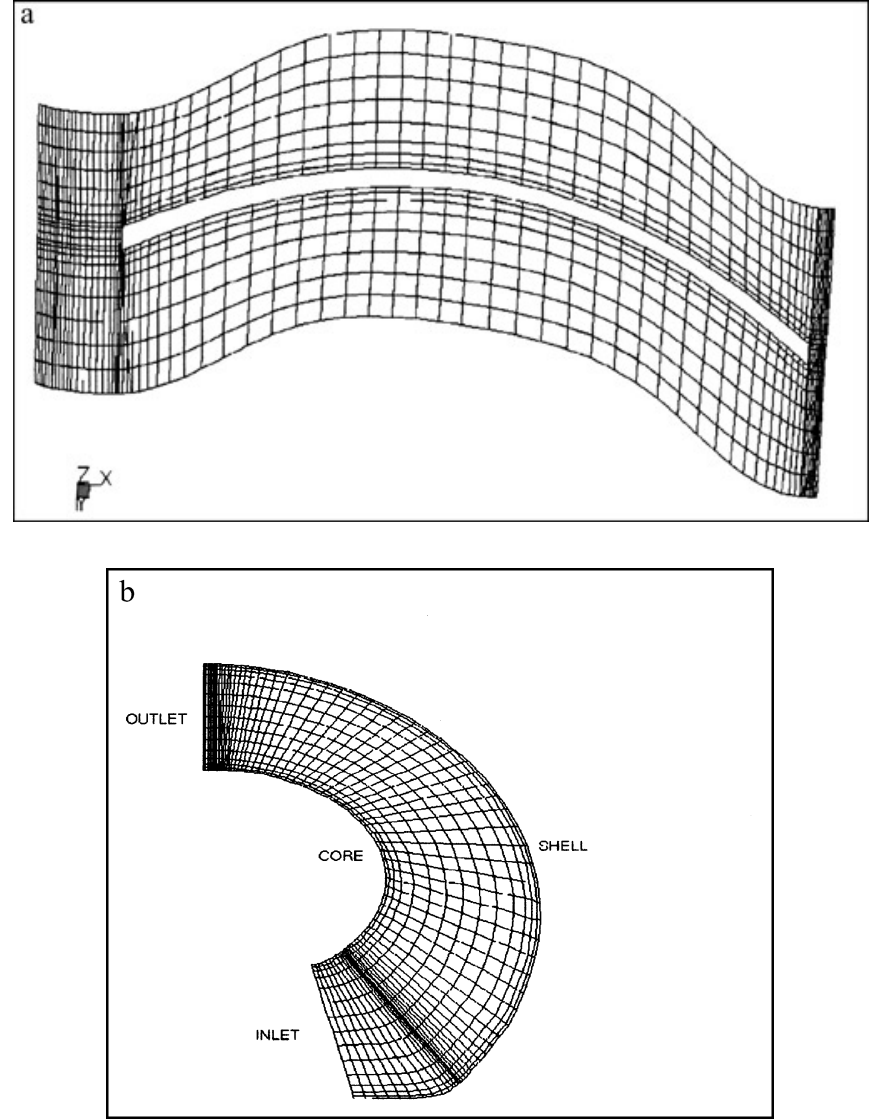

FIGURE 1

(a) Rolled-out view of pump and turbine grid. (b) Meridional view of pump and turbine grid.

\section{SOLVER AND FLOW MODELING CONDITIONS}

CFD analysis was made using a commercially available package, CFX TASCflow (AEA Technology, 2000b). This package includes pre- and postprocessing capabilities and the flow solver. The flow solver is a three-dimensional, Navier-Stokes, finitevolume code capable of solving incompressible, steady-state, transient, laminar, or turbulent fluid flow.

Wall boundary conditions were set on the pressure and suction surfaces of the blade and the shell and core surfaces. This specifies that the fluid cannot flow across the boundary surface and sets the velocity to zero. Periodic boundary conditions were set on the boundary surfaces in the tangential direction. The solution on the pair of boundary surfaces in the tangential direction in each element is identical. A stage interface condition was set between the elements. Thus, all three blade passages were solved simultaneously, with tangential averaging at the interface of the elements using one blade-centered passage from each element. This neglects transient interactions, and only steady-state solutions are obtained. The $\kappa-\epsilon$ turbulent model with log-law wall functions was used. The advection type used was the Modified Linear Profile Scheme (LPS) with Physical Advection Correction (PAC) terms (AEA Technology, 2000b).
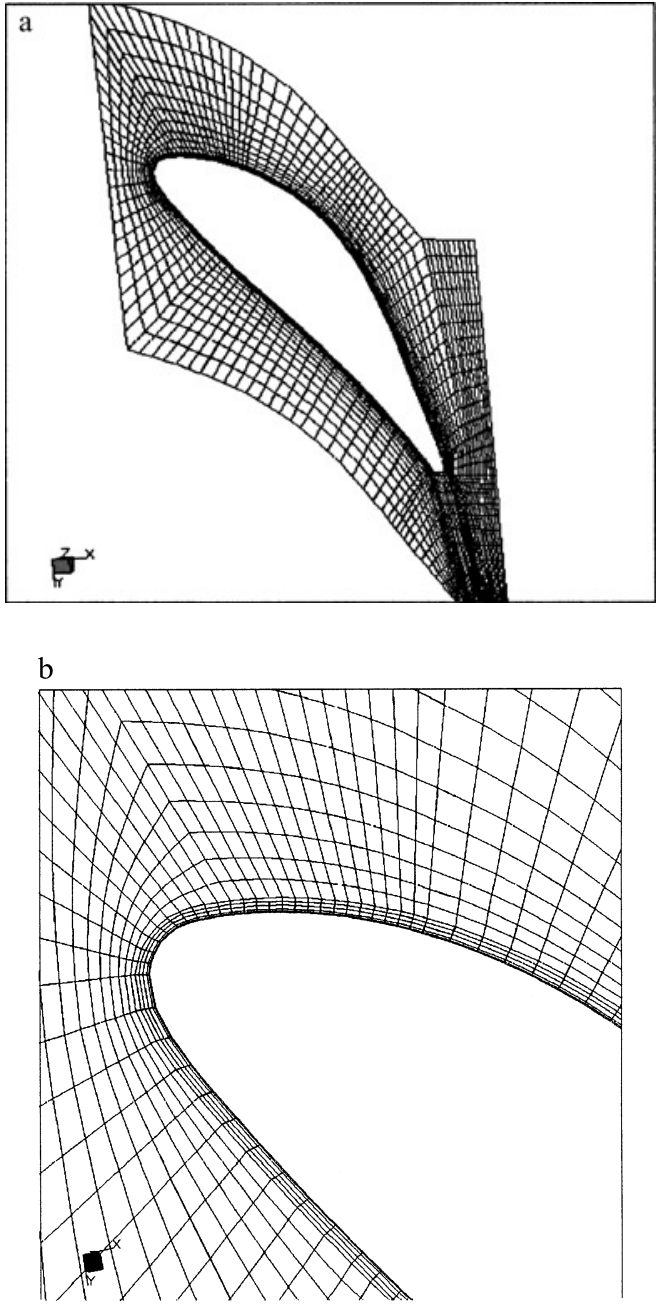

FIGURE 2

(a) Stator grid. (b) Stator leading edge.

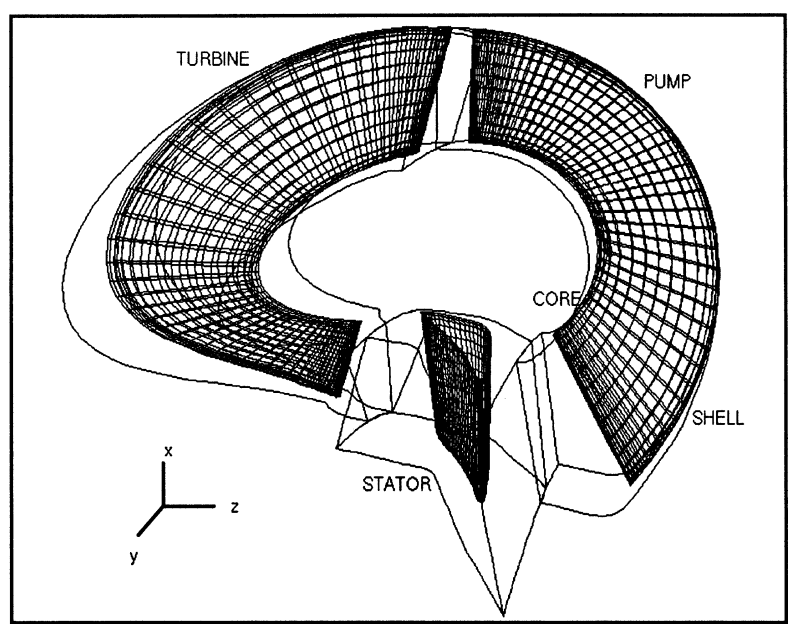

FIGURE 3

Three-dimensional computational model. 


\section{EXPERIMENTAL VALIDATION}

\section{Laser Doppler Velocimetry Data}

Laser Doppler Velocimetry (LDV) is the measurement of fluid velocities by detecting the shift in Doppler frequency of laser light that has been scattered by small particles moving with the fluid. Using this technique, velocities were measured at various locations within the torque converter. A torque converter machined of Plexiglas was used for the experimental work. In order to match the index of refraction of Plexiglas, 1.490, Shellflex 212 , an oil with an index of refraction of 1.489 at $25^{\circ} \mathrm{C}$ and 1.480 at $50^{\circ} \mathrm{C}$, was used. This experimental work was done under a contract by Dr. Ronald Flack and students at the University of Virginia (Brun, 1996; Whitehead, 1995). Work was done on torque converters with various blade and torus shapes and at various speed ratios. Comparison of velocity profiles from CFD simulation and LDV data for one geometry and speed ratio of 0.8 are presented. For the LDV data, the first and last points of the grid were located away from the blade, core, and shell surfaces. It was physically impossible to take measurements close to the walls.

The CFD results of the throughflow velocity at the pump's mid-plane were compared with the LDV data (Fig. 4). The same scale was used for the LDV and CFD plots. As expected, the curvature of the passage pushed the fluid toward the shell-pressure side. Thus, a high velocity region was seen at this corner and a separation region at the core-suction side. The code predicted a smaller separation region than did the LDV data, but the highvelocity region was well predicted. As the fluid moved toward the exit of the pump, the high-velocity region moved to the pressure side. The region of separated flow seen in the mid-plane

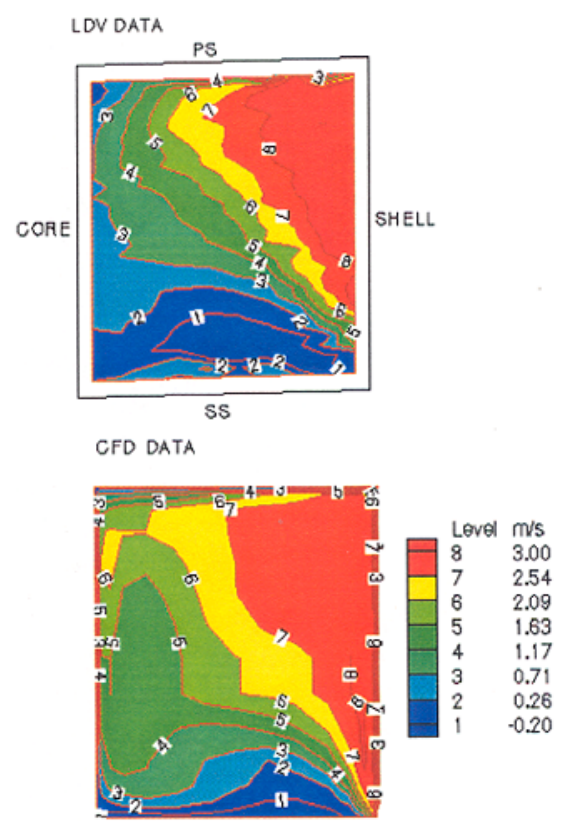

FIGURE 4

Pump mid-plane throughflow velocity.

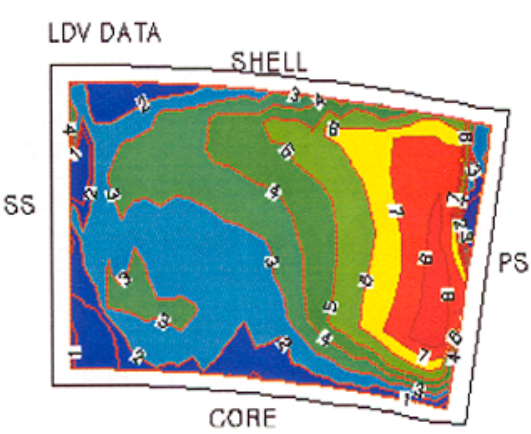

CFD DATA

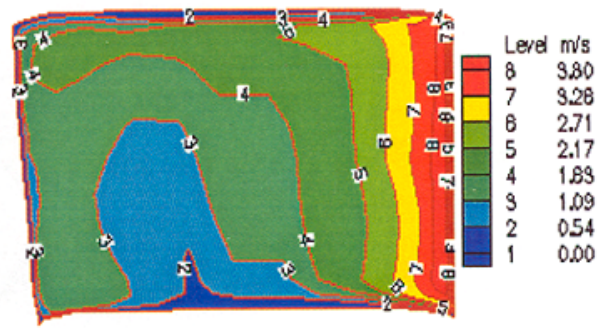

FIGURE 5

Pump exit plane throughflow velocity.

at the core-suction corner has reattached. Only a low-velocity region was seen at the core side. This is shown in Figure 5. The CFD results showed a smaller low-velocity region.

Figure 6 compares the throughflow velocity contours at the turbine's mid-plane. The high-velocity region was located at the pressure side and the low-velocity region at the suction side. The high-velocity region was larger in the pressure-suction direction at the shell side than at the core side. This was more pronounced in the CFD results.

The throughflow velocity at the stator's mid-plane is shown in Figure 7. At high-speed ratios, the flow entering the stator impacted the back of the stator blade, or the suction side. Thus, a large high-velocity region was seen on the suction side and lower velocities on the pressure side. Good agreement was seen between the LDV and CFD results.

\section{Probe Data}

Velocities and pressure were measured at various locations within the torque converter using a high-frequency-response, five-hole probe. This work was done under a contract by Dr. Budugar Lakshminarayana and students at The Pennsylvania State University (Dong, 1998; Liu, 2001). Work was done on torque converters with various blade and torus shapes and at various speed ratios. Pressure profiles from CFD simulation were compared with the probe data for one geometry and a speed ratio of 0.6 . The pressures were normalized using the following equation:

$$
P_{\text {norm }}=\left(P-P_{\text {hub }}\right) / P_{\text {ref }}
$$



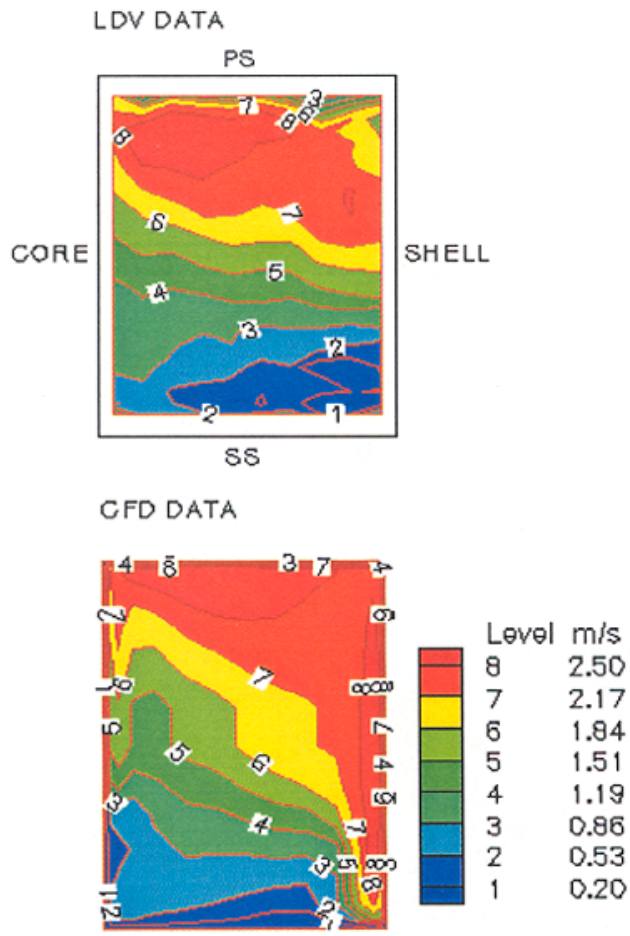

FIGURE 6

Turbine mid-plane throughflow velocity.

where $P_{\text {ref }}=0.5 \rho V_{\text {ref }}^{2}$ and $P_{\text {hub }}$ is the static pressure measured at the stator hub.

Figure 8 compares the normalized static pressure at the pump midplane. The same scale was used for the probe data and the computational data. For the probe data, the first and last data
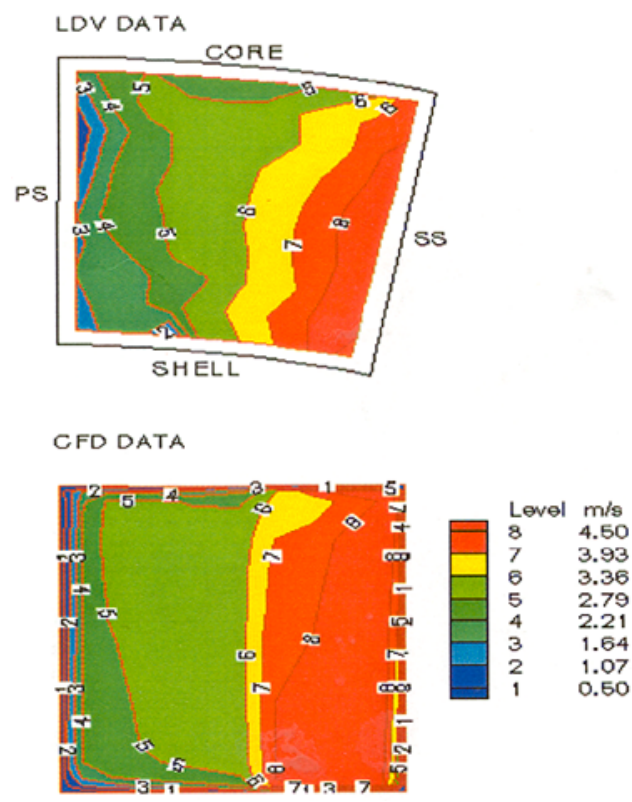

FIGURE 7

Stator mid-plane throughflow velocity.
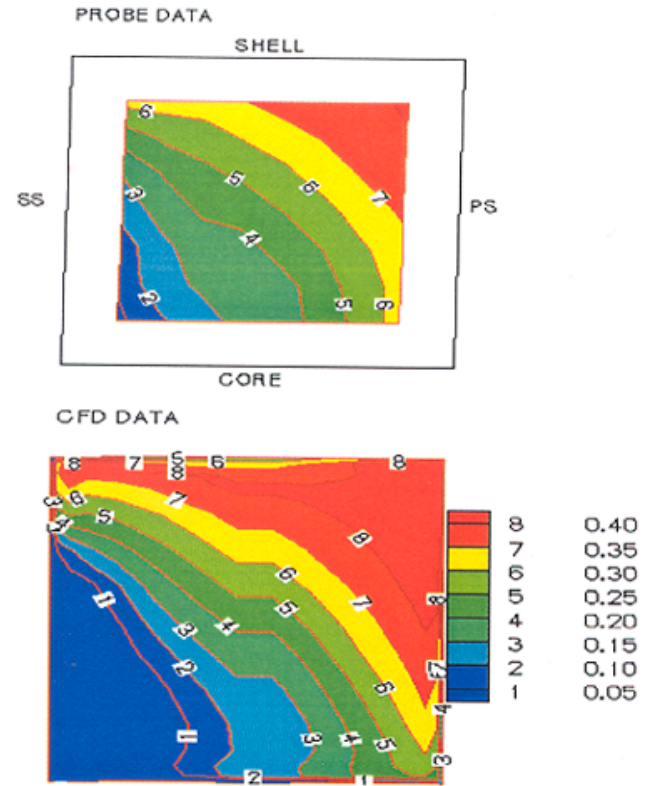

FIGURE 8

Pump mid-plane normalized static pressure.

points were located away from the blade, shell, and core surfaces. Thus, the data close to the walls was not available. Figure 8 shows that the pressure was highest at the shell-pressure side. At the midplane, a torque converter pump shell has a larger radius than at the core so, as expected, the pressure gradient was from the shell-pressure corner to the core-suction corner. The computational data matches well with the probe data.

Figures 9 and 10 show the pressure contours inside the turbine of a torque converter. At the turbine $1 / 4$ plane, the static pressure was highest at the shell. The pressure gradient was primarily in the radial direction and was somewhat underpredicted by the CFD. At the midplane of the turbine, the higher pressure was seen at the shell-pressure corner and the low-pressure fluid was pushed to the core-suction side. At both locations the computational results showed a much larger low-pressure region than did the probe data.

\section{Dynamometer Data}

All of the dynamometer work was done at GM Powertrain (Ypsilanti, MI). A code validation study was done using a combination of pumps and stators, all run with the same turbine. Some of the results, in the form of performance plots, are presented below. The performance parameters are defined as follows:

$K$ factor $=N_{p} / \sqrt{ } T_{p}$

Torque ratio $=T_{t} / T_{p}$

Speed ratio $=N_{t} / N_{p}$

Efficiency $=$ Speed ratio $\times$ torque ratio $\times 100 \%$, where $N_{p}$ and $N_{t}$ are pump speed and turbine speed in rpm, and $T_{p}$ and $T_{t}$ are pump torque and turbine torque in $\mathrm{Nm}$. 

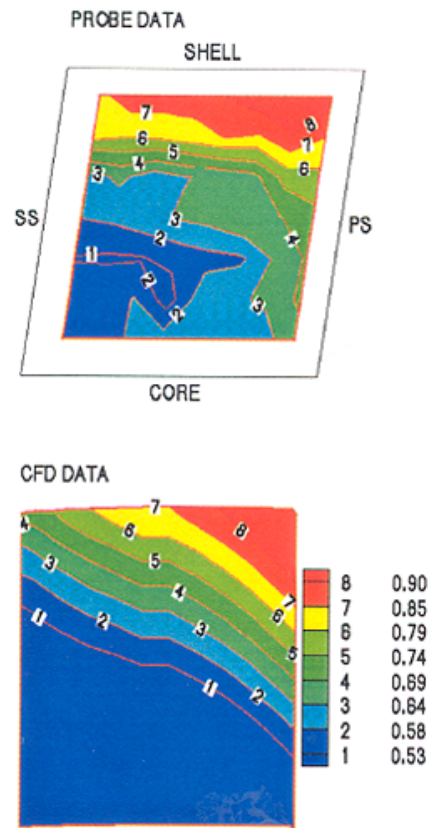

FIGURE 9

Turbine $1 / 4$ plane normalized static pressure.

Six speed ratios were computed from stall to 0.95 for each case. Beyond the coupling point, an iterative procedure was used to set the stator speed such that the stator torque was zero (torque ratio equals 1). Pumps 1 and 2 have positive outlet angles (Figs. 11 and 12), and pump 3 has a negative outlet angle
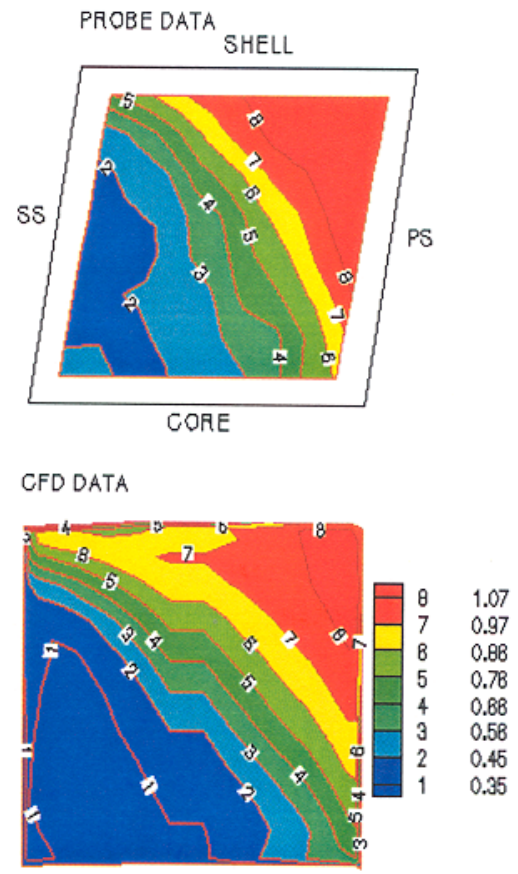

FIGURE 10

Turbine mid-plane normalized static pressure.

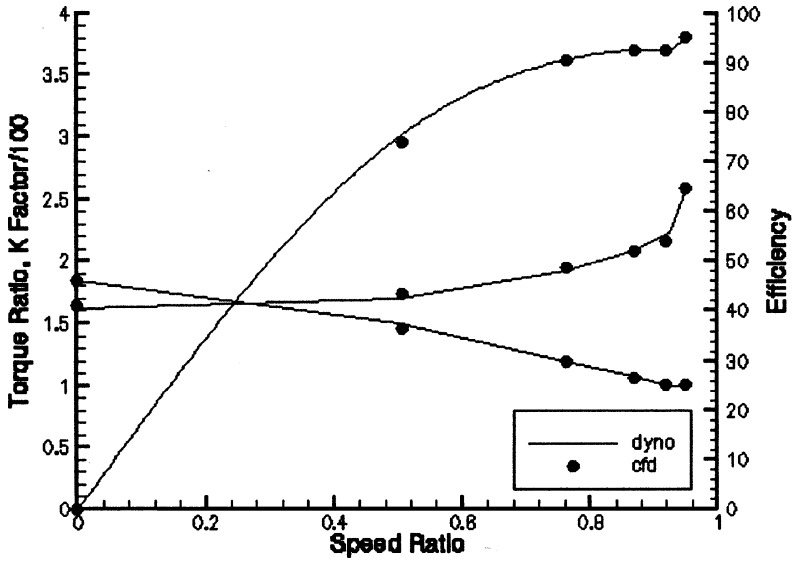

FIGURE 11

Torque converter performance for pump 1, stator 1 .

(Fig. 13). Positive-outlet pumps show a separated region at the mid-passage and no backflow region at the exit, but negativeoutlet pumps have a backflow region at the exit. For this reason the frozen rotor condition had to be used at the pump-turbine interface for pump 3, while the stage-averaging condition was retained at the stator interfaces. To accommodate the pitch difference and the relative angle between the pump and the turbine blades, several simulations with different relative pump-turbine positions were completed for each speed ratio point. The results presented are an average of these simulations. For positive-outlet pumps, the stage-averaging condition was used. As can been seen from Figures 11, 12, and 13, the CFD results match very well with the dynamometer data.

\section{AREAS OF APPLICATION}

The following examples demonstrate how CFD simulations have been used as a design tool for torque converter development, providing faster iterations for improved design optimization and reducing the requirement for physical hardware.

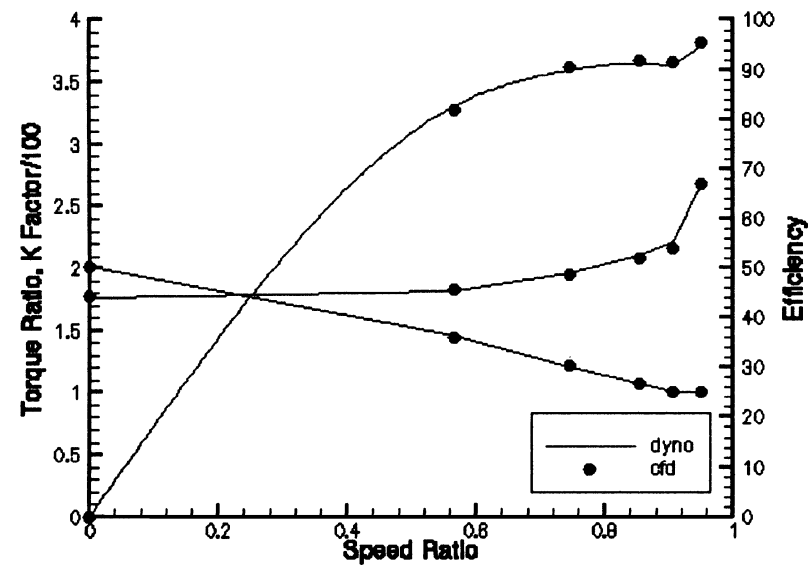

FIGURE 12

Torque converter performance for pump 2, stator 2 . 


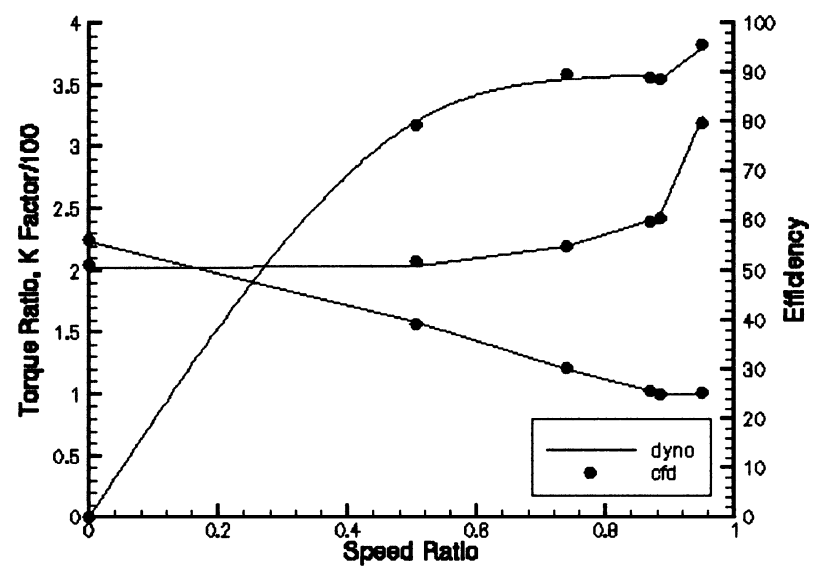

FIGURE 13

Torque converter performance for pump 3, stator 1 .

\section{Element Design}

CFD was used in a project to develop a stator blade design methodology that results with lower torque converter $K$ factor curves at high speed ratios while maintaining the totque ratio and efficiency curves of the baseline design. Figure 14 is a typical torque-converter performance plot that was generated with the results of CFD simulations. The $K$ factor, torque ratio, and efficiency curves are plotted against the speed ratio.

For the simulations, the turbine and pump were fixed, while the stators were varied. Stator 1 was the baseline, and stators 2 , 3 , and 4 had modified blade shapes. The goal of lowering the $K$ factor curve was achieved, while the torque ratio was fairly consistent. The small drop in peak efficiency was considered acceptable. Stators 3 and 4 resulted in the greatest reduction in the $K$ factor (the curves almost overlay each other), but Stator 3 was selected for additional development because it is a supe-

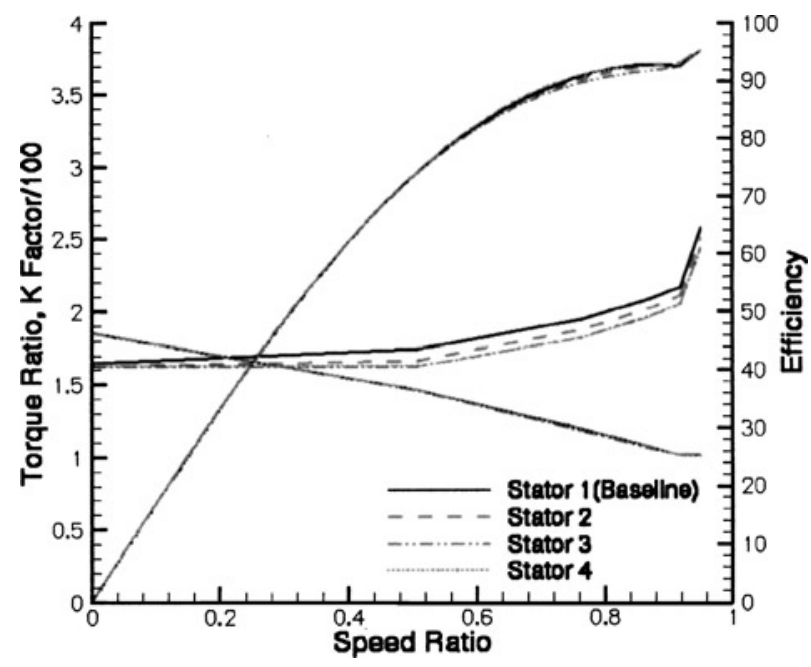

FIGURE 14

CFD predictions of torque converter performance comparing stator blades.

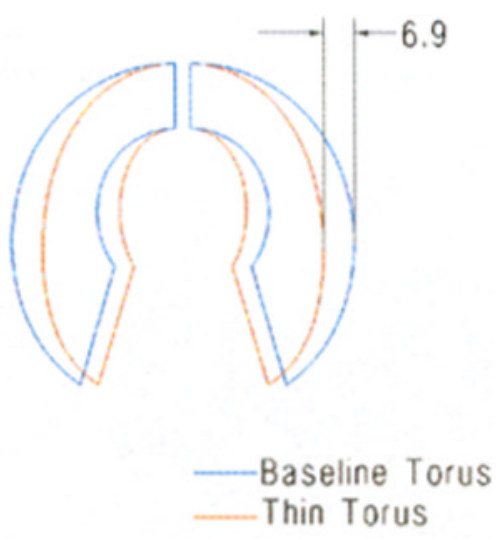

\section{FIGURE 15}

Reduced-width torque-converter torus.

rior structural design. Dynamometer test results matched well with CFD predictions. An example is Figure 11, which was the baseline stator in this application.

\section{Torus Design}

The trend in future automatic-transmission designs is to achieve comparable performance to traditional designs but with reduced mass and in less space. The challenge in torque-converter design is to develop a reduced-width torus without sacrificing efficiency. CFD was used to analyze numerous iterations of torque converters to optimize the torus for the allowed space. Figure 15 shows the baseline torus versus the final torus. Nearly $7 \mathrm{~mm}$ were removed from the half-width with favorable results.

Simulated torque-converter performance curves based on CFD are shown in Figure 16. The inlet and outlet angles of

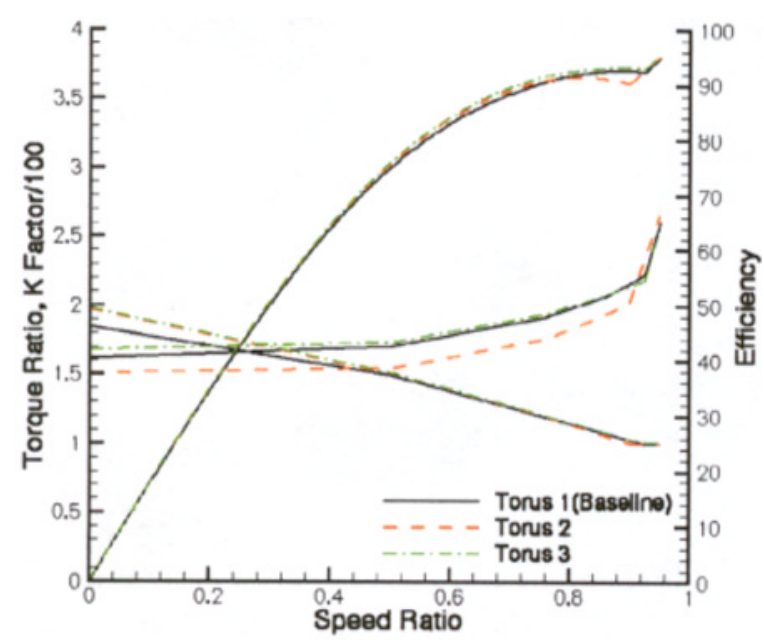

FIGURE 16

CFD predictions of torque-converter performance for various torus designs. 


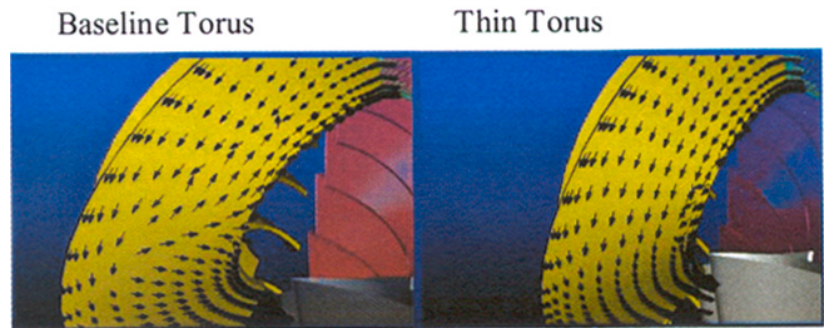

FIGURE 17

Flow vectors in the turbine.

the blades for the thin torus torque converters were the same as for the baseline. Torus 2 used a reduced half-width for the pump and turbine and an axially shorter stator. The CFD simulation predicted a drop in the $K$ factor and peak efficiency. The $K$ factor could be adjusted by modifying the blade angles, but the decreased efficiency would not be acceptable. Numerous iterations of the torus shape were simulated before torus 3 was selected. This torus is nonsymmetrical, using a thin turbine with the baseline pump and stator. The CFD simulation actually predicted greater peak efficiency than that of the baseline torque converter.

Figure 17 demonstrates how CFD results were used to achieve the final torus design. Flow vectors are shown for the original and final torus shapes. The baseline torus shows an area of reverse flow near the midplane of the turbine. Several iterations of torus shapes for the turbine were analyzed using CFD to get to the final torus design, in which the reverse flow was greatly reduced.

Hardware was ordered to validate the CFD predictions. The dynamometer test results are plotted in Figure 18. The torque ratio and $K$ factor curves for the thin torus increased somewhat relative to the baseline, as was predicted by the CFD simulation. The peak efficiency was slightly lower than predicted but was nearly the same as that of the baseline torque converter that is $7 \mathrm{~mm}$ longer.

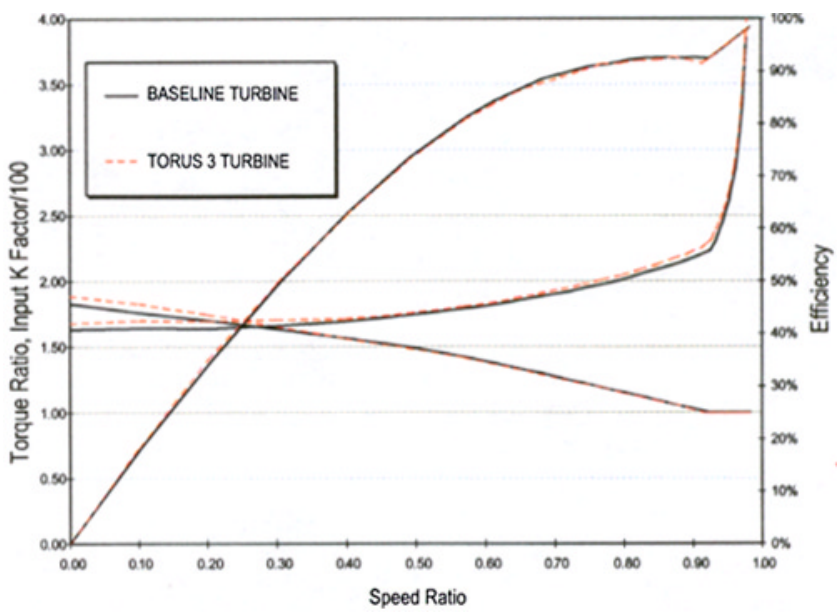

FIGURE 18

Torque-converter performance from dynamometer test.
Traditionally, in the design and development of a new torque converter machined from solid turbines, pumps and stators would have been obtained in order to test several torque-converter combinations. A single machined from a solid torque-converter assembly can take 6 months to procure and cost around $\$ 50,000$. The use of CFD allowed more design iterations in less time and at far less cost than traditional methods.

\section{Cavitation Study}

The final example of the use of CFD is a cavitation study that was done to determine the risk of cavitation in a specific torque-converter application that had the potential of operating at lower-than-normal pressures. The most severe operating condition for cavitation was simulated to check for regions of zero pressure inside the torque converter. Figure 19a is a developed view of the pressure field of the turbine, stator, and pump at stall (turbine speed $=0 \mathrm{rpm}$ ), with pump speed equal

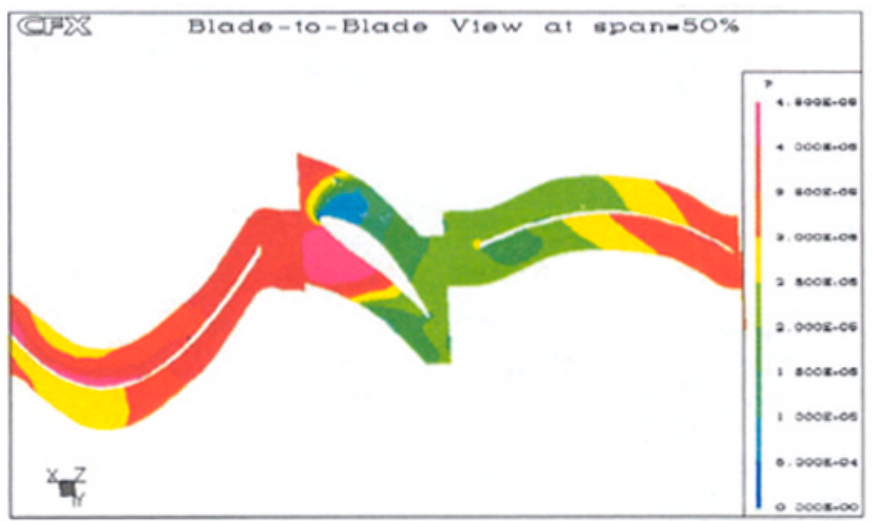

(a)

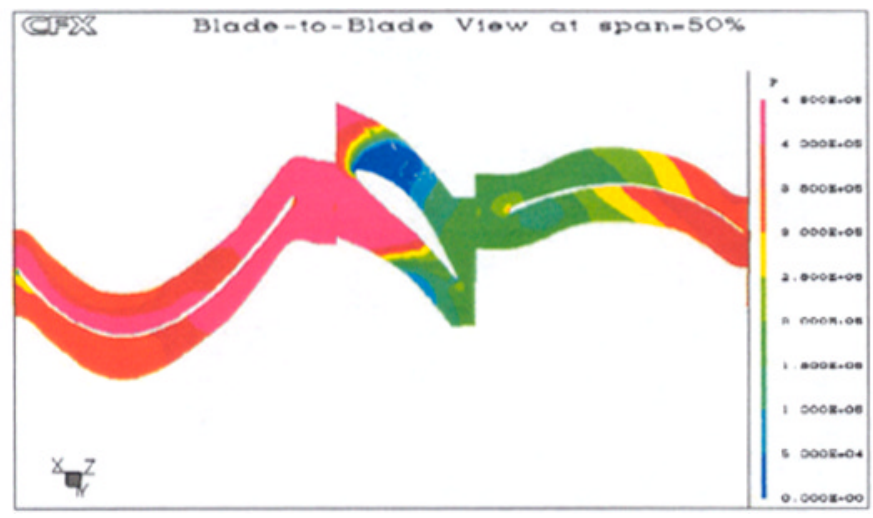

(b)

FIGURE 19

CFD data of pressure (Pa) in a torque converter. (a) Turbine speed $=0 \mathrm{rpm}$; pump speed $=1600 \mathrm{rpm}$; transmission line pressure $=40$ psi. (b) Turbine speed $=0$ rpm; pump speed $=$ $2000 \mathrm{rpm}$; transmission line pressure $=40 \mathrm{psi}$. 
to $1600 \mathrm{rpm}$ and transmission line pressure at $40 \mathrm{psi}$. There is a small region of zero pressure at the nose of the stator blade. When the pump speed was increased to $2000 \mathrm{rpm}$, the zeropressure region spread along the suction side of the stator blade (Fig. 19b). The study showed that there was indeed a high risk of cavitation in the torque converter, so the transmission parameters in this application were changed to avoid such low pressure.

\section{CONCLUSIONS}

Based on the validation studies, it can be concluded that CFD can be used as a design and analysis tool. The correlation between the CFD predictions and the test results was close enough to support the use of CFD as a tool for making decisions about design direction. Final validation using physical hardware cannot be eliminated, but the design can be better optimized before hardware is fabricated. Use of CFD provides the opportunity for more design iterations in less time and at greatly reduced cost as compared to traditional development methods. The result is improved design optimization and better final design.

\section{REFERENCES}

AEA Technology, Advanced Scientific Computing. 2000a. CFX TurboGrid 2000, Version 1.5: User Documentation. Waterloo, Ont., CA: AEA Technology.

AEA Technology, Advanced Scientific Computing. 2000b. CFX TASCflow3D, Version 2.10: User Documentation. Waterloo, Ont., CA: AEA Technology.

Brun, K. 1996. Analysis of the Automotive Torque Converter Internal Flow Field ( $\mathrm{PhD}$ diss, University of Virginia).

Dong, Y. 1998. An Experimental Investigation on Fluid Dynamics of an Automotive Torque Converter ( $\mathrm{PhD}$ diss, The Pennsylvania State University).

Liu, Y. 2001. An Experimental Investigation on Fluid Dynamics and Performance of an Automotive Torque Converter ( $\mathrm{PhD}$ diss, The Pennsylvania State University).

Whitehead, L. D. 1995. A Comparison of the Internal Flow Fields of Two Automotive Torque Converters using Laser Velocimetry. (Master's thesis, University of Virginia). 

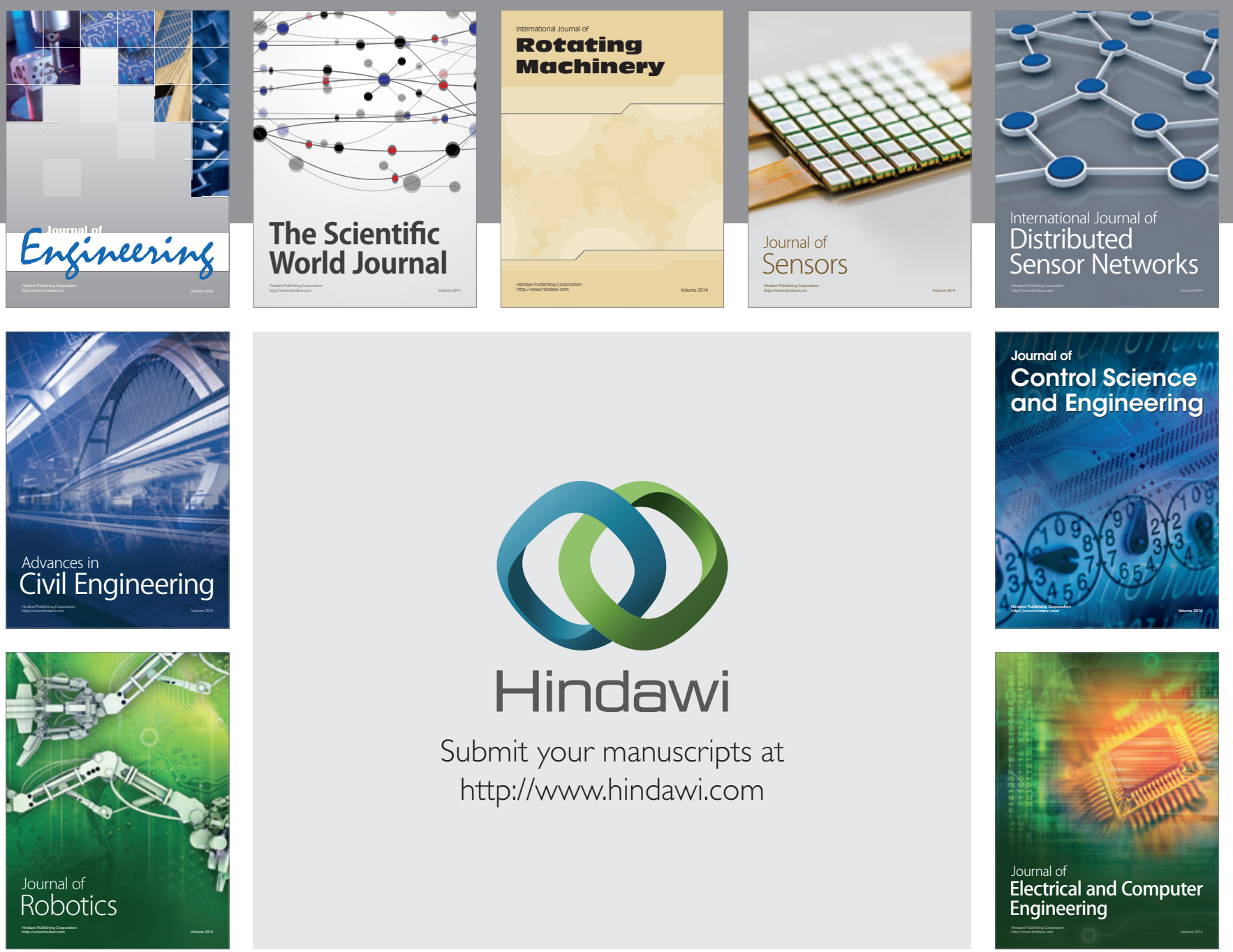

Submit your manuscripts at

http://www.hindawi.com
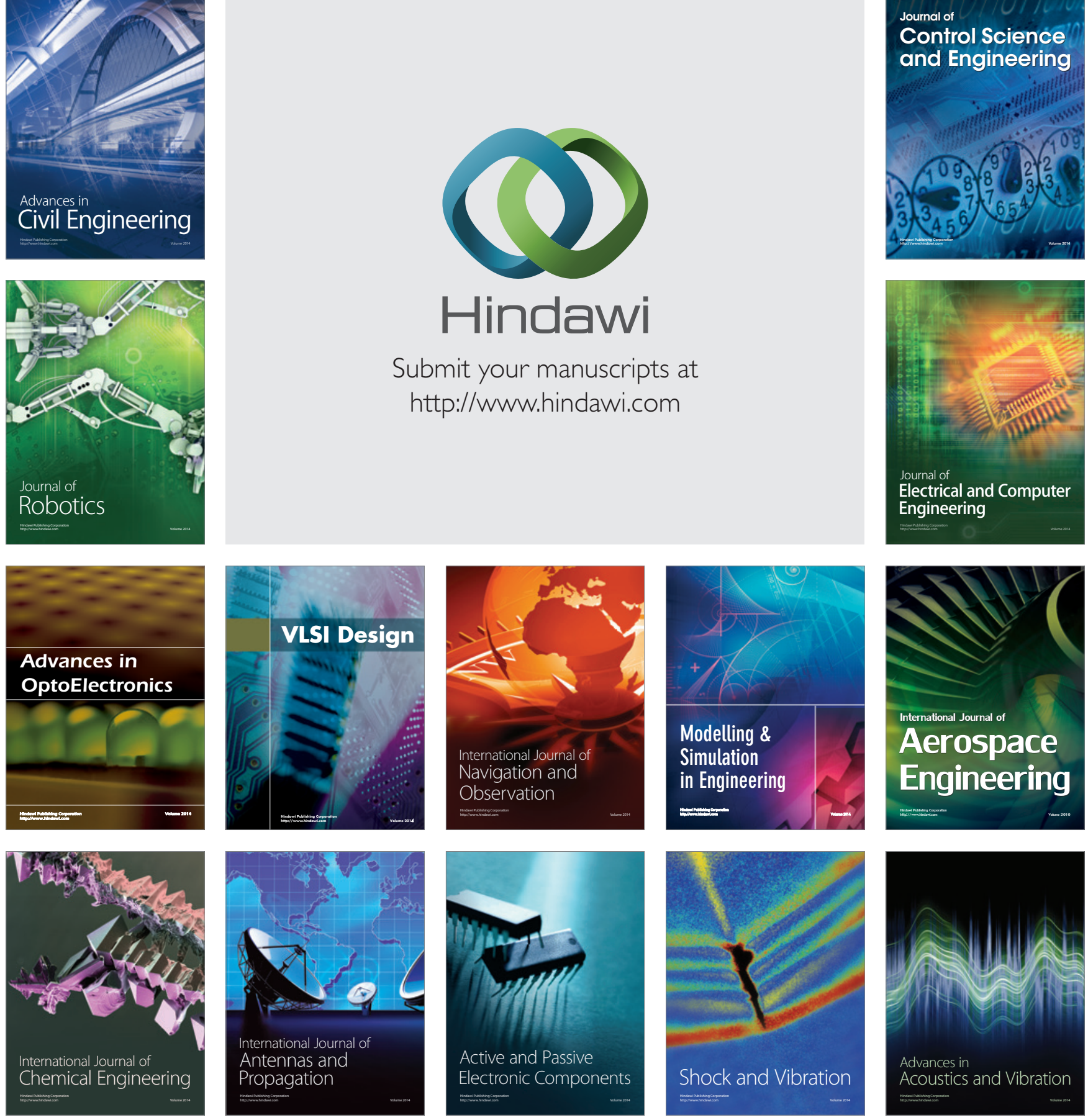